\title{
AS TECNOLOGIAS NA POLÍTICA NACIONAL DE FORMAÇÃO DE PROFESSORES A DISTÂNCIA: ENTRE A EXPANSÃO E A REDUÇÃO
}

\author{
Raquel Goulart Barreto*
}

\begin{abstract}
RESUMO: Este artigo foi produzido a partir de três pontos de entrada: (1) recontextualização; (2) expansão e redução e (3) tutores: concepção e condições de trabalho. Com base neles, discute a inscrição das tecnologias na configuração da política nacional de formação de professores a distância, focalizando os pressupostos e as implicações das formulações que a sustentam.
\end{abstract}

Palavras-chave: Tecnologias. Formação de professores a distância. Tutores. Dimensões técnica e política.

\section{TECHNOLOGIES IN THE NATIONAL DISTANCE TEACHER EDUCATION POLICY: BETWEEN EXPANSION AND REDUCTION}

ABSTRACT: This article has been produced by means of three points of entry: (1) recontextualization; (2) expansion-reduction movement and (3) tutors' conception and working conditions. Based on them, it analyzes the ways information and communication technologies are inscribed in the current distance learning teacher education national policy, by focusing on the assumptions and implications of the formulations which sustain the whole construction.

Key words: Technologies. Distance learning teacher education programs. Tutors. Technical and political dimensions.

Doutora em Educação e docente do Programa de Pós-Graduação em Educação da Universidade do Estado do Rio de Janeiro (UERJ).E-mail: raquel@uol.com.br 
As tecnologias na política nacional de formação de professores a distância...

\section{Os pontos de entrada}

\section{Recontextualização}

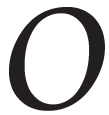

título deste artigo pretende indicar uma abordagem relacional em que o privilégio é atribuído a um modo específico de recontextualização das tecnologias da informação e da comunicação (TIC), ainda que os dois elementos que constituem a relação objetivada suscitem consideraçóes específicas, notadamente no que diz respeito aos pressupostos e à configuração histórica das TIC, bem como da constituição de uma política nacional de formação de professores a distância.

Para introduzir as questôes relativas às TIC, parece oportuno lembrar que estas não mais estão referidas às chamadas "tecnologias educacionais", produzidas visando a sua utilização em situaçôes concretas de ensino-apendizagem. Sua própria designação indica o seu pertencimento a áreas não-educacionais, no sentido de produzidas no contexto de relaçôes sociais outras, com finalidades distintas. Assim, as TIC são descontextualizadas das suas áreas em que foram produzidas e recontextualizadas na educação, implicando apagamentos (Bernstein, 1996) que, para serem dimensionados, exigem a análise das condições e das circunstâncias da sua realização (Fairclough, 2005; 2006).

Em se tratando da inscrição das TIC na política nacional de formação de professores a distância, ora materializada na Universidade Aberta do Brasil (UAB), há uma cadeia de recontextualizações e múltiplas dimensōes a focalizar. O contexto mundial atual tem características aqui sintetizadas na articulação do discurso da "globalização" ao da "sociedade da informação/conhecimento", implicando correlações de força e contornos inéditos, ao mesmo tempo em que são mantidos os imperativos capitalistas. Apenas para citar um exemplo, o lugar de destaque ora atribuído à "universidade", como fornecedora de "Educação Terciária", é indissociável da competitividade como valor maior, mesmo quando a ausência de condiçōes para competir no "mercado" internacional aponta para o aprofundamento da condição capitalista dependente do país. ${ }^{2}$

De acordo com Fairclough (2005), o processo de recontextualização compreende a disseminação de discursos para além das fronteiras de estrutura e de escala. No primeiro caso, trata-se do deslocamento de 
um campo social para outro: não apenas da comunicação e da informação, mas da lógica dos "negócios" para a educação, cada vez mais marcada pela comodificação, na medida em que o próprio campo é deslocado para o setor de serviços, nos termos dos acordos capitaneados pela Organização Mundial do Comércio (OMC) e pelas iniciativas da UNESCO em prol de maior internacionalização dos serviços educacionais. Em se tratando de escala, a recontextualização das TIC pode ser dimensionada pelas formulações das organizações "globais" endereçadas aos Estados nacionais, especialmente quando periféricos.

Por outro lado, é preciso não simplificar as muitas recontextualizações. Como define Fairclough (2006, p. 101), este é "um fenômeno complexo, envolvendo, para além de uma simples colonização, um processo de apropriação cujas características e resultados dependem das circunstâncias concretas dos diversos contextos". Em outras palavras, o foco deste artigo é a recontextualização que a política educacional brasileira em geral e a UAB em particular têm feito das recomendações e condicionalidades estabelecidas para os países periféricos (do Sul), no que tange à incorporação educacional das TIC.

\section{Expansão e redução}

O título do artigo também pretende favorecer o mapeamento do território em que tem sido produzida a recontextualização das TIC, com base no movimento aparentemente contraditório de expansão e redução no encaminhamento das questôes a ela relacionadas. De um lado, a suposição de que as TIC sejam "a solução" para todos os problemas, incluindo os que extrapolam os limites educacionais. De outro, seu uso intensivo está inscrito em estratégias de educação a distância (EaD), em especial para a formação de professores, como proposta de massificação a ser aqui analisada.

A palavra "tecnologias" tende a soar como uma espécie de chavemestra capaz de abrir todos os caminhos e portas: solução mágica para os mais diversos problemas. Há quem defenda que as TIC estão na origem de uma revolução que instaura a "sociedade informática" (Schaff, 1995), ou "da informação/do conhecimento/dos saberes". Esta defesa se funda em pressupostos como o descentramento da categoria "trabalho" e permanece enredada em uma cadeia determinista, contestada 
As tecnologias na política nacional de formação de professores a distância...

por autores como Wood (2003), Felinto (2005) e Mattelart (2002). Este último destaca que "a segunda metade do século Xx foi marcada pela formação de crenças no poder miraculoso das tecnologias informacionais" (p. 172), no "discurso salvador sobre a promessa de concórdia universal, de democratização descentralizada, de justiça social e de prosperidade geral" (p. 31), na convergência dos discursos apologéticos para "atestar o final dos grandes determinantes sociais e econômicos na construção dos modelos de implantação das tecnologias digitais e de suas redes" (p. 146).

Em se tratando da objetivação das TIC, este artigo contesta a "revolução científico-tecnológica" como origem suposta: como se sua produção pudesse ser pensada fora das relações que as engendram, como se fossem determinantes de processos em que também estão enredadas. Assume, com Kellner (s/d), que as TIC têm sustentado mudanças importantes nas práticas sociais, do trabalho ao lazer, passando pelas formas de comunicação, sem desconsiderar as suas continuidades em relação às práticas anteriores, no sentido da preservação dos poderes econômicos e políticos dominantes e do aprofundamento da divisão entre possuidores e despossuídos, na configuração de uma nova forma de tecnocapitalismo global. ${ }^{3}$

São contestados, aqui, dois pressupostos da objetivação hegemônica das TIC: (1) o de que as mudanças sócio-político-econômicas se devam simplesmente a uma "revolução científico-tecnológica"; e (2) o de que as TIC estejam na sua origem (Barreto, 2008). É importante esclarecer que esta contestação não implica minimizar as mudanças representadas pela utilização das TIC, sob pena de perda da perspectiva dialética na abordagem das lutas por hegemonia.

Nos limites deste artigo, o que está em jogo é o modo como a contradição expansão-redução tem sido "resolvida" em termos de política educacional: ao invés de fortalecer as instâncias universitárias de formação docente pela incorporação das TIC, esta promove um modelo de substituição tecnológica. Este modelo, sustentado por uma sucessão de metonímias com implicações substantivas para a formação e o trabalho docente, se encontra esboçado desde a formulação da versão governamental do Plano Nacional de Educação (PNE), aprovado em 2001, em que o título do sexto capítulo evidencia inversão digna de nota: "educação a distância e tecnologias educacionais". ${ }^{4}$ 


\section{Tutor: novo elo na cadeia}

Assumindo a concepção e as condições objetivas de trabalho do tutor como síntese de muitas reconfiguraçôes, este artigo examina quatro Editais de Seleção publicados on-line, contemplando a diferenciação feita pelos programas integrantes da UAB: tutores virtuais, incluindo ou não visitas aos pólos, e tutores de apoio presencial localizados nos pólos. 5

Em todos os Editais, a precariedade das condiçôes para a realização das atividades previstas é explicita. No caso da seleção de tutor virtual para a Universidade Federal de São Carlos:

A remuneração por esta atividade será feita em forma de bolsa de fomento, paga pelo FNDE, no valor de $\mathrm{R} \$ 600,00$, pela carga horária de 20 horas semanais. Ao compor a equipe da UAB-UFSCAR, o tutor virtual será bolsista do MEC-SEED, no programa Universidade Aberta do Brasil, com bolsas pagas pelo FNDE diretamente em conta-benefício do tutor, aberta no Banco do Brasil especificamente para este fim. O recebimento da bolsa não representa ao tutor nenhum vínculo empregatício com a UFSCAR, $o$ que significa que o tutor não tem os mesmos direitos de aluno, funcionário ou professor desta instituição. (Grifos meus)

Na seleção para a Universidade Federal Rural de Pernambuco, permanecem inalteradas as condições (fonte de financiamento, valor percebido a título de bolsa e conseqüente ausência de vínculo), mas há um acréscimo significativo no que se refere à compressão do tempo no cumprimento das tarefas. O texto não apenas faz alusão a "utilizar diariamente os recursos tecnológicos disponibilizados para interagir com os estudantes", como também estabelece prazo exíguo: "esclarecer as dúvidas dos alunos no prazo máximo de 24 horas". Considerando que o tutor não é especialista na(s) área(s) em que deverá atuar, sendo-lhe exigida apenas "formação em graduação na área específica ou afim para a qual está se candidatando", esta compressão parece supor a clareza meridiana ("transparência") dos materiais disponibilizados pelas TIC.

Para resumir as condições impostas aos tutores, é oportuna a citação das Disposições Finais do Edital publicado pela Universidade Federal do Espírito Santo:

Os tutores presenciais receberão uma bolsa de $\mathrm{R} \$ 500,00$, para uma carga horária de 20 horas semanais. Os tutores a distância receberão uma 
As tecnologias na política nacional de formação de professores a distância...

bolsa de $\mathrm{R} \$ 600,00$, para uma carga horária de 20 horas semanais. Nenhum candidato poderá alegar desconhecimento das instruçōes contidas no presente Edital.

Para dimensionar as diferenças entre as bolsas, Masuda (2003) afirma: a tutoria a distância atua nas universidades, fisicamente longe dos alunos, mas próxima aos professores, enquanto a tutoria presencial é realizada nos pólos regionais, em locais próximos aos estudantes e fisicamente distante dos professores. Aos últimos são atribuídas várias tarefas de cunho administrativo, que o Edital da UNIRIO agrupa sob a designação: "atuar em atividades de assistência aos diretores(as) e coordenadores(as) de pólos", abrangendo, entre outras, rotinas como "receber, acompanhar e controlar o processo de distribuição de material didático aos alunos, bem como efetuar a cobrança da segunda via quando necessário"; e "coordenar a organização dos horários e viabilizar o uso dos computadores pelos alunos".

O valor menor da bolsa e o conjunto das atividades de "apoio operacional" exigidas implicam aposta na fragilidade da função, o que parece tentativamente contornado neste mesmo Edital, ao estabelecer que estas vagas "serão ocupadas por profissionais com vínculo com instituição pública (federal, estadual ou municipal)". A formulação sugere que, não configurando vínculo específico, o comprometimento dos tutores de apoio presencial possa ser associado a vínculo pré-existente.

Sobressai, nos quatro casos citados, a consolidação da UAB como instância reguladora, em nível nacional, de bolsas com valores diferentes, ambos pífios, para a mesma função (tutoria), sugerindo a distância dos alunos ou a proximidade dos professores como "valor maior". Aos ocupantes desta função tem sido atribuído grande destaque nas formulações. Exemplificando com Masuda, acima citado, "a tutoria constitui uma ferramenta particularmente importante (...) é impar no sentido de inserir um componente pessoal, humanizando com isto o processo de aprendizagem em educação a distância" (Grifos meus).

Diante desta e de afirmações congêneres, adquire especial relevo a crítica formulada por Zuin (2006, p. 951-952):

(...) o atual linguajar empregado em geral nos textos sobre educação a distância prima pela associação da imagem do professor como um mensageiro, um recurso ou mesmo um prestador de serviços pedagógicos. $\mathrm{O}$ 
emprego de tais predicados denota a existência do fetiche tecnológico que se baliza na supremacia da comunicação secundária sobre a primária, de tal modo que há hoje o sério risco de revitalização do conhecido e malfadado tecnicismo pedagógico.

Sintetizando, o tutor, como figura introduzida no contexto educacional brasileiro pela EaD e como elo mais frágil de toda uma cadeia de simplificações, é um desdobramento previsível do processo de esvaziamento da formação e do trabalho docente (Barreto, 2004), não podendo ser desvinculado da aposta centrada nos materiais ditos "auto-instrucionais" e nas tecnologias para a sua produção e circulação. Como afirmam Evangelista e Shiroma (2007, p. 531), a preocupação com a eficiência e a eficácia do trabalho docente está inscrita "numa lógica racionalizadora, técnica, pragmática, que encontra na defesa abstrata do uso das tecnologias da informação e comunicação sua expressão mais acabada”.

\section{Os encaminhamentos}

\section{EaD: modos de objetivação}

A inscrição das TIC no escopo da EaD estava marcada desde a própria designação da secretaria criada, em 1995, para promover a incorporação educacional das TIC: Secretaria de Educação a Distância (SEED), definida como: "um agente de inovação tecnológica nos processos de ensino e aprendizagem, fomentando a incorporação das Tecnologias de Informação e Comunicação (TIC) e das técnicas de educação a distância aos métodos didático-pedagógicos" (grifos meus). ${ }^{6}$

Retomando a inversão apontada no PNE, no segundo ponto de entrada recortado neste texto, a recontextualização não deixa margem a dúvidas: as TIC são pensadas para a EaD. Nesses termos, a pergunta fundamental é deslocada das diferentes objetivações das TIC, analisadas por Barreto et al. (2006), para os modos pelos quais a EaD tem sido pensada. Recuperando reflexões presentes em texto anterior (Barreto, 2006), é importante dimensionar dois encaminhamentos para o tema EaD: (1) como modalidade de ensino; e (2) como estratégia de formação.

O primeiro modo não envolve necessariamente discussões substantivas, já que, na condição de modalidade de ensino, a EaD tende a ser considerada na sua especificidade em relação ao ensino presencial, 
As tecnologias na política nacional de formação de professores a distância...

com a ênfase posta na dimensão operacional. Vale destacar que se trata da única modalidade que não é nomeada em função do nível de ensino ou da clientela a que se destina, mas ao seu modus operandi, assumindo a centralidade das TIC para a veiculação dos materiais de ensino e para o seu gerenciamento. A discussão tende a assumir como foco a dimensão técnica, tanto no design quanto no controle do processo, e a apresentar, como argumentos de legitimação, a superação de barreiras relacionadas a tempo-espaço com vistas à "democratização" do acesso ao conhecimento.

O segundo modo parte do princípio de que a EaD configura opção assumida no conjunto das políticas educacionais. A ênfase, portanto, é posta nos seus pressupostos e implícitos, no horizonte dos sentidos que lhe são atribuídos no tempo e no espaço. Constitui discussão substantiva que, antes e para além de quaisquer considerações operacionais, aborda a dimensão político-ideológica deste modo de incorporação das TIC, buscando compreender as condições históricas da sua realização. Os argumentos que o sustentam dizem respeito à legitimação desta estratégia, especialmente na medida em que o seu principal alvo tem sido a formação de professores para a educação básica.

Para dimensionar a EaD no discurso oficial visando à configuração atual da UAB, dois momentos são aqui recuperados: (1) o desenho esboçado em 1999 pela UNIREDE, constituída essencialmente como instância de articulação de ações implementadas pelas universidades consorciadas (Oliveira, 2008); e (2) a produção de alternativas para a concretização deste esboço, representada pelo documento produzido pelo Grupo de Trabalho Interministerial (GTI), constituído pelo Decreto de 20 de outubro de 2003, encarregado de apresentar plano de ação visando a reestruturar, desenvolver e democratizar as instituiçôes federais de ensino superior.

Nos dois momentos, o adjetivo recorrente é "estratégico". ${ }^{7} \mathrm{Um}$ dos documentos básicos da UNIREDE é publicado por Faria, Leite e Rondelli (2000), sob o título: "Tecnologia e conhecimento na nova economia. UNIREDE: um projeto estratégico para a educação superior". Originalmente encontrado no site específico, permanece disponível na revista on-line Parcerias Estratégicas, do Ministério de Ciência e Tecnologia.

No relatório produzido pelo GTI, a EaD é assumida como estratégia para dar conta da "constatação" de que a "universidade pública 
brasileira, nos limites impostos pela educação presencial, mesmo com aumento substancial de recursos, não teria condições de aumentar as vagas de forma maciça" (p. 13, grifos meus). Assim, a EaD é posta como alternativa para multiplicar o número de alunos sem alterar significativamente os quadros docentes e os investimentos. ${ }^{8}$ A tutoria é um fator importante nesta operação que inclui outras providências como:

(...) capacitação de pessoal docente e equipes multimídias [sic]; implantação de redes com alto grau de comunicação e de interatividade; produção de materiais educacionais que garantam larga utilização; fortalecimento do apoio logístico a alunos e docentes, tanto na sede, quanto em pólos descentralizados; além do desenvolvimento e implantação de sistemas adequados de gestão, operacionalização, acompanhamento e avaliação. (p. 14 , grifos meus)

A ênfase na gestão configura o desenho da estratégia assumida como tal. No momento atual, justamente quando da implantação de um sistema nacional de formação de professores a distância, o substantivo (estratégia) e o adjetivo (estratégico/a) parecem ter caído em desuso, tendendo a EaD a ser discutida nos limites da condição de modalidade de ensino, o que equivale a reduzir as questões envolvidas à sua dimensão técnica.

\section{UAB: para além da dimensão técnica}

O portal da UAB, em discurso muitas vezes circular, partindo dos pólos e a eles retornando, tem como diferencial o número sempre crescente destes mesmos pólos. ${ }^{9}$ A arquitetura parece simples e pronta para agregar o que mais remeta ao cumprimento das metas estabelecidas no PNE em relação ao número de vagas oferecidas na educação superior. Como a fundamentação da proposta não é objetivada, a suposta existência de "técnicas de educação a distância" (conforme citação da SEED) é retomada através da referência à "metodologia" de EaD e os textos ficam restritos à dimensão operacional das formulações, sugerindo estar, no privilégio da técnica, a estratégia política fundamental da UAB. Como afirma Freitas (2007, p. 1214):

As iniciativas atuais de massificação, por intermédio da UAB, cumprem as metas estatísticas e conformam os professores a uma concepção de caráter 
As tecnologias na política nacional de formação de professores a distância...

subordinado, meramente instrumental, em contraposição à concepção de educador de caráter sócio-histórico, dos professores como profissionais da educação, intelectuais essenciais para a construção de um projeto social emancipador que ofereça novas possibilidades à educação da infância e da juventude.

Esta massificação é posta como uma espécie de democratização ilimitada, conforme texto precedido pelo ícone de alerta no link "Sobre a UAB": trata-se de um "sistema" de articulação de instituições existentes para "levar ensino superior público de qualidade aos municípios brasileiros que não possuem cursos de formação superior ou cujos cursos ofertados não são suficientes para atender a todos os cidadãos".

Em relação a este alerta, é importante marcar dois aspectos: (1) a definição dos espaços a serem ocupados pela UAB aponta também a ressignificação de "distância" - da geográfica para a das vagas -, considerando a impossibilidade de vagas para “todos”, especialmente em um contexto ainda de luta pela universalização da escola básica; e (2) a restrição ao ensino público contraria as disposiçōes relativas à diversificação dos "fornecedores" (Barreto, 2008) no projeto elaborado pelo Fórum das Estatais pela Educação (2005, p. 10): "deverá a UAB promover uma interação mais ampla, seja atuando também com empresas que não são exclusivamente estatais, assim como com as demais instituiçôes de educação superior, sejam públicas, sejam privadas".

Assim, é possível afirmar que a UAB configura estratégia desenvolvida em condições muito favoráveis aos seus fins: é concebida como fundação de direito privado que, na forma de consórcio entre estatais, prefeituras e universidades públicas e privadas, sob a coordenação de um Conselho Gestor, constituído, entre outras entidades, pela Confederação Nacional da Indústria, organiza cursos a distância, em especial para promover a formação/certificação de professores, contando com acompanhamento/avaliação da chamada Nova CAPES.

Entre as mudanças dignas de nota na rota da UAB, está o seu financiamento que, de acordo com o art. 6o do Decreto n. 5.800, de 2006, é inscrito nas "dotações orçamentárias anualmente consignadas ao Ministério da Educação e ao Fundo Nacional de Desenvolvimento da Educação - FNDE". Logo, a UAB não teria a mesma "flexibilidade" das fundações. Por outro lado, isto não impediu que Resolução n. 44 do FNDE, publicada em 02/01/2007, estabelecesse orientações e diretrizes para a concessão de bolsas de estudo e pesquisa no exercício de $2006 .{ }^{10}$ 
$\mathrm{Na}$ tentativa de compreender o processo de implantação e os rumos da UAB, ultrapassando os limites associados às fontes secundárias, a alternativa seria a busca de informaçōes no portal do MEC. Neste movimento, a partir de referência de 2006, só foi possível encontrar, em várias tentativas, uma mensagem inusitada para quem não é hacker: ${ }^{11}$

\section{Figura 1}

Mensagem do portal do MEC

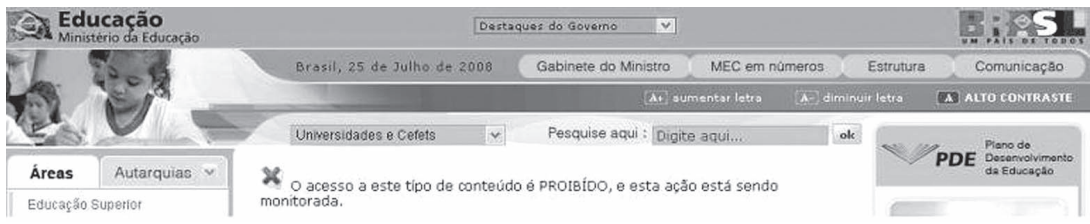

Rejeitando o pressuposto da disponibilidade de "todas" as informaçōes na internet, a partir do qual o acesso à rede tem sido metonimicamente tomado pela "democratização do conhecimento", é relevante pontuar que não se trata aqui do processo de apagamento/substituição de arquivos ao longo do tempo, nem mesmo da exigência de senhas e/ ou pagamentos específicos, mas de proibição seguida de "advertência".

Nos limites do acesso permitido e no território circunscrito por este artigo, as "fortes parcerias" anunciadas no portal da UAB não podem ser desvinculadas das formulações do já citado Fórum das Estatais pela Educação:

A estrutura básica da UAB e dos Consórcios deve se assemelhar mais a uma "fábrica", enfatizando a alta produção de cursos (planejamento curricular e pedagógico; preparação de roteiros de cursos; produção audiovisual; de textos de acompanhamento; atendimento a suporte ao aluno; avaliação do aluno e do curso), via várias formas tecnológicas. (p. 10 , grifos meus)

TIC para quê?

Nesta última seção, o propósito é sistematizar os encaminhamentos produzidos a partir dos três pontos de entrada (recontextualização, 
As tecnologias na política nacional de formação de professores a distância...

expansão-redução e tutoria) nas relações entre as TIC e a constituição de uma política nacional de formação de professores a distância, centralizada na/pela UAB. Sem pretender dar conta das múltiplas dimensões envolvidas nesta inscrição, o foco é a proposta de massificação assumida, destacando pressupostos que a viabilizam e implicaçôes para o contexto educacional brasileiro atual.

A ênfase na multiplicação dos pólos de formação de professores, especialmente a partir da tomada da "fábrica" como parâmetro, traz à tona a industrialização do ensino. No caso, a produção em série de professores é pensada como resultado do acesso às TIC, considerando os materiais de ensino veiculados através delas, com a eliminação de mediações pedagógicas historicamente constitutivas do processo de formação. $\mathrm{O}$ argumento central tem sido referido a valor incontestável ("democratização"), em um discurso circunscrito à racionalidade instrumental. Neste entremeio, questóes precisam ser formuladas.

A questão central remete a uma implicação importante: a re-instauração oficial da dualidade educacional (Gramsci, 1984). ${ }^{12} \mathrm{Na}$ medida em que é configurada uma política nacional de formação de professores a distância, apartada da presencial, não apenas modalidades de ensino são postas em jogo, mas é promovida cisão radical. ${ }^{13}$ Sem ignorar as restrições que têm sido postas à formação de professores em geral, como a concepção de ensino desvinculado da pesquisa (Barreto, 2002), o destaque aqui é a constituição de sistema paralelo supostamente mais democrático e, sem dúvida, mais defensável em termos de viabilidade econômica. Ou seja, o que está em questão é o "barateamento" desta formação, nos seus diferentes sentidos.

Como a proposta do sistema paralelo não contempla discussóes relativas aos seus fundamentos, pode sugerir a hipertrofia da dimensão operacional: as TIC, os materiais, os pólos, os tutores etc. A cadeia de simplificações, reiterada ao longo deste texto, remete a uma abordagem neotecnicista, cujo núcleo é a substituição tecnológica fundada na articulação do reducionismo (TIC para a EaD) à sofisticação. Objetos cada vez mais sofisticados podem ser postos a serviço da "fábrica", visando à produção de cada vez mais professores. ${ }^{14}$

A aposta nas TIC agrega à proposta o toque da desejada modernização, ao mesmo tempo em que joga uma espécie de cortina de fumaça sobre a distinção entre o acesso propriamente dito e modos pelos 
quais ele é produzido, bem como os sentidos de que estes modos são investidos. A indistinção, recontextualizada em escalas mais amplas, permite que qualquer acesso seja tomado pela transposição do "divisor digital", concebido como fronteira entre os incluídos e os excluídos na/ da chamada revolução científico-tecnológica.

Sem negar o acesso aos diferentes produtos do trabalho humano, as TIC obviamente incluídas, como condição necessária a qualquer proposta democrática, é preciso reconhecer que o acesso em si não é suficiente. ${ }^{15} \mathrm{~A}$ apropriação, como horizonte, requer o reconhecimento de fronteira mais complexa, colocando de um lado os que podem até mesmo modificar as aplicações da tecnologia e, de outro, os consumidores de pacotes, limitados a operações tão simples quanto previsíveis. Em se tratando da recontextualização educacional das TIC, este reconhecimento remete à superação de condiçôes restritivas, unidirecionais, como o lugar de usuário que recebe, em "pacotes tecnológicos", informações pré-selecionadas a serem apreendidas, retidas e (com)provadas. ${ }^{16}$

A aposta nas TIC, nas condições em que tem sido produzida, pode se (con)fundir com a centrada nos materiais ditos "auto-instrucionais", para usar uma expressão cara ao tecnicismo dos anos de 1970 . Concebidos como auto-explicativos, dispensam a mediação pedagógica propriamente dita. No máximo, requerem tutores que permitam aos "clientes" tirar dúvidas derivadas das "suas" dificuldades de leitura. $\mathrm{Na}$ medida da sua disponibilidade, estes materiais apontam para a secundarização do ensino, em nome de uma aprendizagem dita "autônoma” ou seguida de outra adjetivação positiva. Em outras palavras, o binômio ensino-aprendizagem pode ser apagado pelo estabelecimento de uma relação direta, muitas vezes automática, entre TIC e aprendizagem, no "mercado educacional", sintagma que, por conta da tendência discursiva à comodificação, pode nem mais provocar estranhamento.

A cadeia de simplificações pode ser extensa: as TIC, os pacotes e os tutores no lugar do trabalho docente, a ausência de discussôes coletivas, o aligeiramento que descaracteriza a formação, a derrama de diplomas e certificações, a prática apartada da pesquisa, a suposta posse das respostas no lugar do encaminhamento de questões formuladas a partir das situações concretas vividas pelos sujeitos que ensinam e aprendem etc.

Portanto, diante da disponibilidade cada vez maior das TIC, cujos interesses comerciais parecem poder permanecer intocados, e de 
As tecnologias na política nacional de formação de professores a distância...

propostas que cada vez mais se expandem, como o credenciamento dos programas de pós-graduação a distância, é preciso formular perguntas que permitam redimensionar a sua recontextualização educacional: TIC para quê? Para quem? Em que termos?

Finalmente, em nome da coerência na explicitação dos pressupostos, o encaminhamento destas perguntas, assim como dos seus vários desdobramentos possíveis, está fundado na perspectiva de que as TIC não podem ser recontextualizadas apenas para simplificar ou substituir as práticas sociais, especialmente nos países ao "Sul" da dita "sociedade global da informação", sob pena de aprofundar as desigualdades a serem pretensamente superadas. A recontextualização das TIC, sem expansão e redução, pode agregar mais valor e sentidos à formação profissional, em especial daqueles cujo trabalho será precisamente o docente. ${ }^{17}$

$\mathrm{Na}$ medida em que as perguntas citadas demandariam a escritura de outro artigo, o encerramento deste é feito com uma síntese das negações fundamentais. TIC para quê? Não para promover a distância dos sujeitos, a multiplicação do seu número, a redução do tempo e o aligeiramento dos processos.

Em se tratando do conjunto das medidas que configuram a atual política de $\mathrm{EaD}$, retomados os pontos de entrada que sustentam este artigo (recontextualização, expansão-redução, concepção e condições de trabalho dos tutores), é importante reiterar que o contexto prioritário de aplicação dessas medidas tem sido a formação de professores. Esta recontextualização, agora institucionalizada na condição de política nacional, não pode ser vista apenas como alternativa para superar obstáculos como distância geográfica e escassez de professores formados, tentativamente legitimada por argumentos que variam em torno de "melhor a EaD do que nada", deslocando as questões de fundo, despolitizando-as por meio de medidas encaminhadas e discutidas apenas do ponto de vista operacional, como se o privilégio da dimensão técnica não fosse investido de sentido político determinado.

A recontextualização das TIC na política nacional de formação de professores a distância tem sido produzida pela negação das condições históricas da formação e do trabalho docente, sustentando e sendo sustentada pelo discurso da "falta" e pela proposta de preenchimento através de um conjunto multiplicável de novidades (há sempre algo "novo" 
afirmado como necessariamente positivo). Do pólo da concepção do ensino desvinculado da pesquisa, traduzida em diretrizes curriculares que apontam para o esvaziamento da formação nas instâncias universitárias, ao pólo das fontes de financiamento inacessíveis a estas, a nova fundação tem por alicerce a substituição tecnológica radical: assume que quem educa os educadores são os materiais veiculados através das TIC, ficando as eventuais dúvidas por conta dos tutores.

Em síntese, a política nacional de formação de professores a distância até pode sugerir movimentos de aproximação centrados na sua fragilidade. Entretanto, as condições da sua produção e o escopo assumido apontam no sentido oposto, trazendo para o centro da discussão as implicações deste projeto que, a um só tempo, ampliando e reduzindo a recontextualização das TIC em todo o país, leva ao limite a substituição tecnológica e atinge a institucional.

Recebido e aprovado em julho de 2008.

\section{Notas}

1. Este artigo é baseado em duas pesquisas financiadas pelo CNPq: "As tecnologias da informação e da comunicação nas políticas de formação de professores: os sentidos da reconfiguração de trabalho-formação docente" e "Tecnologias na educação: sentido hegemônico e condições de produção".

2. Abordagem circunstanciada desta correlação de forças pode ser encontrada no artigo Do discurso e das condicionalidades do Banco Mundial, a educação superior "emerge" terciária, de Barreto e Leher, a ser publicado na Revista Brasileira de Educação (no prelo).

3. Ao analisar o cenário mundial, Jessop (2008), na conferência proferida em evento realizado em Lancaster (Critical Discourse Analysis and Social Research), destacou a centralidade dos sentidos ora atribuídos aos 3 Ts: talento, tecnologia e tolerância, em ordem alfabética e não de importância.

4. A datação pura e simples da Lei n. 10.172 permite o apagamento da disputa por projetos que a precedeu: o da Sociedade Brasileira, discutido e consolidado no I e no II Congresso Nacional de Educação (disponível em: <http://www.adunb.org/adunb_online/2007/ pne.pdf >) e o substitutivo assumido pelo MEC.

5. Pela ordem, os Editais citados são: (1) UFSCAR. Disponível em: <http://www.uab.ufscar.br>. Acesso em: 22 out. 2007; (2) UfRPE: Bacharelado em Sistemas de Informação e Licenciatura em Computação. Disponível em: <http://200.17.137.110:8080/ead/concursos/selecaosimplificada-tutor-uab>. Acesso em: 23 jun. 2008; (3) UFEs: Curso de Logística - Especialização. Disponível em: <http://www.neaad.ufes.br/arq_uteis/2_inscricoes_tutores_ logistica.pdf>. Acesso em: 20 jun. 2008; e (4) UNIRIO: Curso de Especialização em Educação Especial. Disponível em: <http://www.unirio.br/cead/tutorpresencial/pdf/edital.pdf>. Acesso: 25 jun. 2008.

Educ. Soc., Campinas, vol. 29, n. 104 - Especial, p. 919-937, out. 2008 
As tecnologias na política nacional de formação de professores a distância...

6. Cabe registrar que esta definição é a atual. Disponível em: <http://portal.mec.gov.br/seed/ index.php?option=content\&task=view\&id=153\&Itemid=290>. Acesso em: 24 jul. 2008.

7. Ambos os documentos, analisados por Barreto (2006), retomam princípio definido na Lei n. 10.172: "Ao introduzir novas concepções de tempo e espaço na educação, a educação a distância tem função estratégica: contribui para o surgimento de mudanças significativas na instituição escolar e influi nas decisões a serem tomadas pelos dirigentes políticos e pela sociedade civil na definição das prioridades educacionais" (p. 54, grifo meu).

8. Análise do documento produzido pelo GTI se encontra em "A educação a distância na reforma universitária”. Jornal da ADUFRJ, 15 mar. 2004, disponível em: <http://www.adufrj.org.br>.

9. Nos limites deste artigo, não são discutidas as estratégias de viabilização deste aumento, questão sem dúvida relevante. Cabe pontuar que as consideraçôes aqui se referem ao portal atual (http://www.uab.capes.gov.br), embora o anterior, com imagens muito instigantes (Barreto, 2008), continue disponível em: <http://mecsrv70.mec.gov.br/webuab>. Acesso em: 26 jul. 2008.

10. A Resolução detalha os valores a serem pagos por meio do FNDE aos participantes do Sistema, mantendo os valores previstos no anteprojeto da fundação de direito privado, como $\mathrm{R} \$ 600,00$ para tutores a distância e $\mathrm{R} \$ 500,00$ para tutores presenciais. De acordo com o documento "Universidade Aberta do Brasil: faz-se necessário denunciar o engodo" (disponível em: <http://www.andes.org.br/univ_nova_engodo.htm>, acesso em: 22 de maio de 2008), ainda que os valores totais desembolsados não estejam explícitos, é possível recorrer ao detalhamento do anteprojeto para chegar a aproximadamente 100 reais mensais por aluno. De um lado, uma espécie de "milagre" para cumprir a meta de expansão do PNE. De outro, "nem tudo que se refere à UAB tem um financiamento tão reduzido. Uma visita à página Transparência Pública do próprio MEC nos ensina que há outros atores em jogo. Procedimentos que dispensam licitações concederam, por exemplo, em 29/12/06, à Fundação Empreendimentos Científicos e Tecnológicos, ligada à unB, contratos de, respectivamente, $\mathrm{R} \$ 416,4$ mil e de $\mathrm{R} \$ 120$ mil, a título de cooperação técnica para implantação da UAB".

11. A referência em questão diz respeito a documento de apresentação do Fórum das Estatais pela Educação, está presente em: <http://www.apufsc.ufsc.br/_menu/2_boletins/2006/ 541/boletim541.pdf> e é (ou era): <http://portal.mec.gov.br/arquivos/pdf/texto.pdf>. O link apontou para <http://portal.mec.gov.br/index.php?proibido=1>. Acesso (consignado na mensagem) em: 25 jul. 2008.

12. Sem desconsiderar que esta dualidade, sem a chancela oficial, não deixou de estar presente na configuração assumida pelo trabalho pedagógico das "escolas interessadas" nas classes dominantes ou subalternas.

13. A propósito, ver apresentação de Pino (2008) na Conferência Nacional de Educação Básica (CONEB). Disponível em: <http://www.cedes.unicamp.br>. Acesso em: 22 mai. 2008.

14. Por outro lado, a suposta centralidade das TIC é posta em xeque nos contextos "em que o acesso é mais difícil. O que é redimensionado são as tecnologias mesmas, sendo defendido o uso de materiais impressos, produzidos em nível central e distribuídos aos professores, desde que acompanhados de algum tipo de variação em torno de manual de instruçōes" (Barreto, 2004, p. 1194).

15. Programas oficiais, em diferentes níveis, envolvem financiamento facilitado ou mesmo a distribuição de laptops com vistas à melhoria da educação. 
16. Para usar expressão central em Paulo Freire, também é possível uma "educação bancária" tecnologicamente embalada.

17. Para usar expressão corrente no discurso pedagógico, "professores são multiplicadores". Fica a pergunta: para além dos pólos, o que o projeto da UAB pretende multiplicar?

\section{Referências}

BARRETO, R.G. Formação de professores, tecnologias e linguagens: mapeando novos e velhos (des)encontros. São Paulo: Loyola, 2002.

BARRETO, R.G. Tecnologia e educação: trabalho e formação docente. Educação \& Sociedade, Campinas, v. 25, n. 89, p. 1181-1201, dez. 2004.

BARRETO, R.G. Política de educação a distância: a flexibilização estratégica. In: Lopes, A.C.; MACEDO, E. (Org.). Politicas de currículo em múltiplos contextos. São Paulo: Cortez, 2006. p. 187-204.

BARRETO, R.G. Recontextualizing information and communication technologies: the discourse of educational policies in Brazil (19952007). Journal for Critical Education Policy Studies, v. 6, n. 1, May 2008. Disponível em: $<$ http://www.jceps.com/?pageID=article\&articleID= 117>. Acesso em: 25 jun. 2008.

BARRETO, R.G. et al. As tecnologias da informação e da comunicação na formação de professores. Revista Brasileira de Educação, Rio de Janeiro, v. 11, n. 31, p. 31-42, 2006.

BERNSTEIN, B. A estruturação do discurso pedagógico. Petrópolis: Vozes, 1996.

BRASIL. Congresso Nacional. Plano Nacional de Educação; aprovado pela Lei n. 10.172/2001. Disponível em: <http://portal.mec.gov.br/ arquivos/pdf/pne.pdf>. Acesso em: 14 jul. 2008.

BRASIL. Ministério da Educação. Fórum das Estatais pela Educação. Projeto: Universidade Aberta do Brasil. 2005. Disponível em: <http:// portal.mec.gov.br/arquivos/pdf/universidade.pdf>. Acesso em: 25 jul. 2008.

BRASIL. Ministério da Educação. Fundo Nacional de Desenvolvimento da Educação. Resolução $\mathrm{FNDE} / \mathrm{CD} / \mathrm{n}$. 044, de 29 de dezembro 
As tecnologias na política nacional de formação de professores a distância...

de 2006. Disponível em: <ftp://ftp.fnde.gov.br/web/resolucoes_2006/ res044_29122006.pdf>. Acesso em: 23 jul. 2008.

BRASIL. Presidência da República. Decreto n. 5.800, de 8 de junho de 2006. Dispóe sobre o Sistema Universidade Aberta do Brasil - UAB. Disponível em: <http://www.planalto.gov.br/ccivil_03/_Ato20042006/2006/Decreto/D5800.htm>. Acesso em: 23 jul. 2008.

BRASIL. Presidência da República. Grupo de Trabalho Interministerial. Bases para o enfrentamento da crise emergencial das universidades federais e roteiro para a Reforma Universitária Brasileira. Brasília, DF, 2003. Disponível em: <http://www.andes.org.br/anexo-circ02104.doc>. Acesso em: 20 jul. 2008.

EVANGELISTA, O; SHIROMA, E.O. Professor: protagonista e obstáculo da reforma. Educação \& Pesquisa, São Paulo, v. 33, n. 3, p. 531-541, set./dez. 2007

FAIRCLOUGH, N. Blair's contribution to elaborating a new 'doctrine of international community'. Journal of Language and Politics, v. 4, n. 1, p. 41-63, 2005.

FAIRCLOUGH, N. Language and globalization. London: Routledge, 2006.

FARIA, D.S.; LEITE, S.D.; RONDELLI, E. Tecnologia e conhecimento na nova economia; UNIREDE: um projeto estratégico para a educação superior. Parcerias Estratégicas, Brasília, DF, n. 9, p.71-83, out. 2000. Disponível em: <http://ftp.mct.gov.br/ceE/revista/Parcerias9/ 08revista9unirede.PDF>. Acesso em: 25 jun. 2008.

FELINTO, E. A religiāo das máquinas: ensaios sobre o imaginário da cibercultura. Porto Alegre: Sulina, 2005.

FREITAS, H. A (nova) política de formação de professores: a prioridade postergada. Educação \& Sociedade, Campinas, v. 28, n. 100, p. 1203-1230, set. 2007.

GRAMSCI, A. Os intelectuais e a organização da cultura. Rio de Janeiro: Civilização Brasileira, 1984.

KELLNER, D. Globalization, technopolitics and revolution. Disponível em: <http://www.gseis.ucla.edu/faculty/kellner/papers/GlobTPRevForan.htm>. Acesso em: 16 jul. 2008. 
MASUDA, M.O. O sistema de tutoria nos cursos do Centro de Educação Superior a Distância do Estado do Rio de Janeiro (CEDERJ). Disponível em: <http://www.tvebrasil.com.br/sALTO/boletins2003/edu/tetxt3_3.htm>. Acesso em: 17 jul. 2008.

MATTELART, A. História da sociedade da informação. São Paulo: Loyola, 2002.

OLIVEIRA, D.M. A formação de professores a distância para a nova sociabilidade: análise do "Projeto Veredas" de Minas Gerais. 2008. Tese (Doutorado em Educação) - Faculdade de Educação, Universidade Federal Fluminense, Niterói.

SCHAFF, A. A sociedade informática: as conseqüências sociais da segunda revolução industrial. São Paulo: UNESP; Brasiliense, 1995.

WOOD, E.M. Democracia contra capitalismo: a renovação do materialismo histórico. São Paulo: Boitempo, 2003.

ZUIN, A.A.S. Educação a distância ou educação distante?: o Programa Universidade Aberta do Brasil, o tutor e o professor virtual. Educação \& Sociedade, Campinas, v. 27, n. 96, p. 935-954, out. 2006. 